\title{
Investigation of Immunomodulation Activity in the Leaves of Dalbergia dissoo
}

\author{
Savita Dixit* and Shikha Rana \\ Maulana Azad National Institute of Technology, India
}

Submission: January 22, 2017; Published: March 01, 2018

*Corresponding author: Savita Dixit, Maulana Azad National Institute of Technology, India, Email: savitadixit1@yahoo.com

\begin{abstract}
During the proper functioning of the immune system reactive oxygen or nitrogen species are generated. These can affect by inducing oxidative damage. This condition occurs with ageing and with diseases. This condition can be annihilated by introducing the defaces by antioxidants. Dietary supplementation with antioxidants can prove to be a stepping stone in these conditions. Natural compounds from plants having rich sources of antioxidants can act as immunomodulators.
\end{abstract}

Aim: The aim of the present study is to investigate the immunomodulation activity in the extracts of Dalbergia Sissoo leaves. This includes in vitro testing of $D$. Sissoo leaves methanolic extract for its antioxidant activity and phytochemicals.

Material and methods: The leaves of D. Sissoo are collected from a Sai nursery situated near Manisha market in Bhopal. These leaves were then washed and the disinfected and were then shade dried for 2 weeks and then grinded in the grinder. After grinding these were taken for extraction. The extraction was done by Soxhlet Method. The tests for antioxidant activity includes DPPH Scavenging activity, NO Scavenging activity, total antioxidant activity and phytochemical tests were performed according to standard methods as proposed by Harborne.

Results and conclusion: The extract have excellent amount of flavonoids and phenolic contents which agrees to the rich antioxidant activity in the leaves extract. Various photochemical are also present in the extract. It is found that these leaves extract are excellent source of antioxidants and can be used as potent immunomodulator.

Keywords: Immunomodulation; Antioxidant activity; D. Sissoo Leaves; DPPH scavenging; NO scavenging; Total antioxidant activity

\section{Introduction}

Medicinal plants have a compelling role in modern and ancient cultures. Diverse active principles have been originated from the conventional medicinal plants. WHO evaluates that $70 \%$ of humans still depends on the herbal medication. India is a rich source of herbal flora and medical systems used here are ancient [1]. The Indian medicinal systems are categorized into classical and traditional systems. These systems cover adapted systems and Indian originated systems which include Ayurveda, Siddha, Unani, Yoga and Naturopathy [2]. Ayurveda principally uses plant based formulations for treatment [3]. The synthesis of aromatic substance by plants is nearly inexhaustible. Most of the substances isolated are secondary metabolites which are estimated to be less than $10 \%$ of the total [4]. Very few of these metabolites have been investigated phytochemically. The percentage submitted to biological and pharmacological screening is even lower. As plants have myriad of metabolites many researchers are turning their concerns into medicinal plant research as it is the most emerging source for possible new lead compounds which can then be taken into therapeutically screening programmes. Plant based drugs are an important source of therapeutic agents because of their abundant availability, relatively cheaper cost and non-toxic nature when compared to modern medicine [5]. There is an enormous demand for the medicinal plants. Antioxidant property of various plants is being investigated because of the health benefits. An antioxidant is a molecule which is efficient in slowing or preventing the oxidation of other molecules [6]. Oxidation is a chemical reaction that transfers electron from a substance to an oxidizing agent. Oxidation reactions can produce free radicals, which start chain reactions that damage cells [7]. Antioxidants cease these reactions by removing the intermediates [8].

The modulation of immune system using plant products as a therapeutic measure is serving as an active scientific investigation. The most ancient of such practices are found in the Vedic scriptures. Immunomodulation could provide an alternative to conventional therapeutics under the conditions of impaired immune responsiveness. This concept also generates credibility when it is found that herbal antioxidants concurrently 
exhibit immunomodulatory activities such as Shilajit and Awleha [9]. Many plants claim to induce Para immunity, non-specific immunomodulation of essentially granulocytes, macrophages, natural killer cells and complement functions [10]. The impetus behind this study was to detect Phyto remedy for boosting immunity which can be used against chemotherapeutics. This study also aims at productive leverage of the plant parts available for medicinal use.

Dalbergia Sissoo belongs to family Fabaceae and has its habitat alongside the foothills of Himalayas of India, Pakistan and Nepal. It is mostly stated for its reputed medicinal properties. Medicinal properties include as an aphrodisiac, abortifacient, expectorant, anthelmintic and antipyretic. Different plant parts such as roots, bark, wood, leaves and seeds are widely used for treating many diseases. It is a folk remedy for excoriations, gonorrhoea, and skin ailments [11]. The leaf extracts of D. Sissoo have shown antipyretic and some analgesic activities due to the presence of alcoholic compounds. Certain ayurvedics also prescribe leaf juice for eye ailments [12]. In India and Nepal, rural people used leaves of $D$. Sissoo to treat animals with diarrhoea [13].

Leaves extract shows positive antioxidant activity. Its leaves extract has considerable number of flavonoids. Studies confirm that chronic bacterial infections can be prevented and treated by preparing a herbal preparation containing D. Sissoo and Datura stramoium [14]. Leaves juice is found to enrich the blood [15-17]. The oil of D. Sissoo has showed a strong repellent action [18]. Wood and bark were used by ayurvedics for treating anal disorders, blood diseases, burning sensations, dysentery, dyspepsia, leukoderma, and skin ailments whereas Yunani used it for blood disorders, burning sensations, eye and nose disorders, scabies, scalding urine, stomach problems, and syphilis. Antioxidants are found in the bark and are used for inflammatory disorders [19]. It is found that the bark and wood are bitter, hot, acrid, aphrodisiac, abortifacient, expectorant, anthelmintic and antipyretic allays thirst, vomiting, burning sensation, cures skin diseases, troubles of the anus, ulcers, and diseases of the blood, leukoderma, dyspepsia and dysentery [20]. The tannins extracted from the bark have been incorporated for various medicinal objectives.

In India D. Sissoo (Shisham) is considered as a promising blood purifier and is also being used to treat Leprosy. The bark leaves and roots are most used parts of the plant and are used as stimulant and astringent [21]. Various traditional healers claim that bark is the most and frequently used part. The bark of the roots has antidiarrheic properties also the smoke of the burning roots is inhaled as a treatment for headaches and bronchitis. The medicinal uses of roots are due to the presence of tectoridin. The roots can also be used to treat abdominal pain, hernia, gonorrhoea, and in abortion. Oil obtained from the seeds is used to cure skin diseases [22].

According to the previous studies it is clear that D. Sissoo is an important medicinal plant. Various parts of it are used for medici- nal properties. The present study aims to find the antioxidant activity in the methanolic extract of leaves of Dalbergia Sissoo and correlate it to immunomodulation. Previously many compounds have been extracted from leaves. Biochenin A, kaempferol, quercetin, kamempferol-3-0-/3-D-glucoside, quercetin-3--L-rhamnoside, rutin, $\beta$-sitosterol were isolated from the leaves of Dalbergia Sissoo [23]. The Oligosaccharides were also isolated from the leaves of Dalbergia Sissoo [24]. Sissosterol isolated from petroleum ether extract of Dalbergia sissoo leaves has also been reported to show significant antiinflmmatory activity [25]. Biochenin A 7-0-[ $\beta$-D-apiofuranosyl- $(1 \rightarrow 6)^{\wedge}$-D-glucopyranoside, Biochenin A 7-0--D-apiofuranosyl- $(1 \rightarrow 5)$ - $\beta$-ü-apiofuranosyl $(1 \rightarrow 6)-\beta$-ü-glucopyranoside], tectorigenin 7-0-[ $\beta$-ü-apiofuranosyl $(1 \rightarrow 6)-\beta$-ü-glucopyranoside], prunetin $\quad 4^{\prime}-0-^{\wedge}-D$-apiofuranosyl- $(1 \rightarrow 6)^{\wedge}$-D-glucopyranoside], 7-methyltectorigenin $\quad 4^{\prime}-0-^{\wedge}$-D-apiofuranosyl- $(1 \rightarrow 6)^{\wedge}$-D-glucopyranoside], genistein $8-0-[\beta-\ddot{v}-$ glucopyranoside] and prunetin 4'-0-[ $\beta$-0- glucopyranoside] have also been isolated from the leaves of Dalbergia Sissoo [26]. Sissotrin has been reported from the leaves [27]. Many studies have been done on various parts of D. Sissoo plant but this study is mainly directed towards study of methanolic extract of leaves.

\section{Materials and Methods}

\section{Plant material}

The leaves of D. Sissoo are collected from a Sai nursery situated near Manisha market in Bhopal. These leaves were then identified Dr Abhishek Gupta, Director, CMBT. These leaves were then washed and the disinfected. These leaves were the shade dried for 2 weeks and then grinded in the grinder. After grinding these were taken for extraction.

\section{Extraction process}

The Soxhlet extraction has widely been used for extracting valuable bioactive compounds from various natural sources. It is used for the comparison of new extraction alternatives. The small amount of the dried powdered material is placed in the thimble. The thimble is placed in distillation flask which contains methanol and water as solvent (70:30). After reaching to an overflow level, the solution of the thimble-holder is aspirated by a siphon. Siphon unloads the solution back into the distillation flask. This solution carries extracted solutes into the bulk liquid. Solute is remained in the distillation flask and solvent passes back to the solid bed of plant. The process runs repeatedly until the extraction is completed. The above method is used in accordance to [28].

\section{Preliminary phytochemical screening}

For screening the phytochemical constituent's standard methodologies given by Harborne [29] were adopted (Table1).

\section{Antioxidant activity}

Following methods were used to study the antioxidant activity of $D$. Sissoo Leaves extract. 
DPPH free radical scavenging activity: The free radical scavenging activities of the extracts were determined by using 2, 2-Diphenyl-1-picrylhydrazyl (DPPH) free radical scavenging method [30]. DPPH in oxidized form gives a deep violet color in methanol. An antioxidant compound donates the electron to DPPH thus causing its reduction and in reduced from its color changes from deep violet to yellow. The free-radical scavenging activities were tested by their ability to bleach the stable radical DPPH. The antioxidant activity using the DPPH (1,1-diphenyl-2Picrylhydrazyl) assay was assessed by this method. The sample extracts and standards (BHA and ascorbic acid) were prepared at various concentrations $(200-1000 \mathrm{ppm})$ and mixed with ethanolic solution of DPPH with a concentration of $0.04 \mathrm{mg} / \mathrm{ml}$. After stand for $20 \mathrm{~min}$ in the dark, the mixtures were measured at $517 \mathrm{~nm}$ against ethanol as blank using UV-Vis Spectrophotometer.

The percentage inhibition of DPPH by extracts was calculated by using following formula

$$
\text { Scavenging Activity }(\%)=\frac{(\text { Abs Control-Abs Sample })}{\text { Abs Control X } 100}
$$

Nitric oxide radical scavenging activity: The procedure is based on the principle that, sodium nitroprusside in aqueous solution at physiological $\mathrm{pH}$ spontaneously generates nitric oxide which interacts with oxygen to produce nitrite ions that can be estimated using Griess reagent. Scavengers of nitric oxide complete with oxygen, leading to reduced production of nitrite ions. Plant extract was dissolved in distilled water for this quantification. Sodium Nitroprusside $(5 \mathrm{mM})$ in standard phosphate buffer saline $(0.025 \mathrm{~m}, \mathrm{pH} 7.4)$ was incubated with different concentration $(100-400 \mu \mathrm{g} / \mathrm{ml})$ of methanol extract and tubes were incubated at $29{ }^{\circ} \mathrm{C}$ for 3 hours. Control experiment without the test compounds but with equivalent amount of buffer was conducted in an identical manner. After 3 hours, incubated samples were diluted with $1 \mathrm{ml}$ of Griess reagents. The absorbance of the colour developed during diazotization of Nitrite with sulphanilamide and its subsequent coupling with Napthylethylenediamine hydro-chloride was observed at $550 \mathrm{~nm}$ on spectrophotometer. Same procedure was done with ascorbic acid which was standard in comparison to methanol extract. Calculated the \% inhibition by formula and plot graph in compared to standard.

$$
\text { Nitric Oxide }(\%)=\frac{\left(\mathrm{A}_{\text {control } \left.^{-\mathrm{A}_{\text {test }}}\right) \times 100}^{\mathrm{A}_{\text {test }}}\right.}{\text { }}
$$

Where,

$$
\begin{aligned}
& \mathrm{A}_{\text {control }}=\text { Absorbance of control reaction } \\
& \mathrm{A}_{\text {test }}=\text { Absorbance in the presence of the samples of extract. }
\end{aligned}
$$

Total antioxidant activity: Determination of total antioxidant capacity was evaluated by the Phosphomolybdenum method [31]. $0.3 \mathrm{ml}$ of extract and sub-fraction in ethanol, ascorbic acid used as standard (5to $200 \mathrm{~g} / \mathrm{ml}$ ) and blank (ethanol) were combined with $3 \mathrm{ml}$ of reagent mixture separately and incubated at $95^{\circ} \mathrm{C}$ for $90 \mathrm{~min}$. After cooling to room temperature, the absorbance of each sample was measured at $695 \mathrm{~nm}$ against the blank. Ascorbic acid was used as standard and the total antioxidant capacity is expressed as equivalents of ascorbic acid or Gallic acid. The antioxidant activity is expressed as the number of equivalents of ascorbic acid and was calculated by the following equation:

$$
\mathrm{A}=\frac{(\mathrm{c} \times \mathrm{V})}{\mathrm{m}}
$$

Where,

$\mathrm{A}=$ total content of antioxidant compounds, $\mathrm{mg} / \mathrm{g}$ plant extract, in Ascorbic Acid Equivalent,

$\mathrm{c}=$ the concentration of Ascorbic acid established from the calibration curve, $\mathrm{mg} / \mathrm{ml}$,

$\mathrm{V}=$ the volume of extract $(\mathrm{ml})$, and

$\mathrm{m}=$ the weight of crude plant extract $(\mathrm{g})$.

\section{Total flavonoid content}

A clean test tube was taken and $0.5 \mathrm{ml}$ of the sample (Extract) is added, containing $1.25 \mathrm{ml}$ of distilled water. Then $0.075 \mathrm{ml}$ of $5 \%$ sodium nitrite solution is added and allowed to stand for $5 \mathrm{~min}$. $0.15 \mathrm{ml}$ of $10 \%$ aluminium chloride is added, after $6 \mathrm{~min} 0.5 \mathrm{ml}$ of $1.0 \mathrm{M}$ sodium hydroxide was added and the mixture were diluted with another $0.275 \mathrm{ml}$ of distilled water. The absorbance of the mixture at $510 \mathrm{~nm}$ was measured immediately. The flavonoid content was expressed as mg querecitin equivalents/g sample.

\section{Total phenolic content}

$1.0 \mathrm{ml}$ of sample was mixed with $1.0 \mathrm{ml}$ of Folin and Ciocalteu's phenol reagent. After $3 \mathrm{~min}, 1.0 \mathrm{ml}$ of saturated $\mathrm{Na}_{2} \mathrm{CO}_{3}(\sim 35 \%)$ was added to 2,3 the mixture and made up to $10 \mathrm{ml}$ by adding distilled water. The reaction was kept in the dark for $90 \mathrm{~min}$, observed under UV-Vis spectrophotometer at 760nm absorbance. Gallic acid was used as a standard with varied concentration from $200 \mathrm{ppm}$ to $1000 \mathrm{ppm}$. A calibration curve was constructed with different concentrations of tannic acid $(0.02-0.1 \mathrm{mM})$ as standard. The results were expressed as $\mathrm{mg}$ of catechol equivalents/g of extract [32].

\section{Results}

The phytochemical analysis of the extracts of $D$. Sissoo leaves revealed the presence of Carbohydrates, steroids, proteins, Alkaloids, sulphates, chlorides, flavonoids, saponins whereas Tannic acid and phenolic compounds are absent (Table 1). In vitro antioxidant activity of methanolic extract of Dalbergia Sissoo leaves were evaluated by DPPH method using ascorbic acid as standard. This method is largely used because of its simplicity and stability [33,34]. It is based on the decoloration reaction between nitrogen electron (from $\mathrm{DPPH}+$ ) and hydrogen atom of the hydroxyl group (from the antioxidant) [35]. The results of the DPPH activity are shown in Table 2. 
Table1: Preliminary Phytochemical Screening of $D$. Sissoo Leaves.

\begin{tabular}{|c|c|c|c|}
\hline S.No. & Phytochemical & Name of Test & D. Sisoo Leaves Extract \\
\hline 1 & Carbohydrates & Molisch test & +ve \\
\hline 2 & Steroids & Salkowiski test & +ve \\
\hline 3 & Proteins & Millions Test & +ve \\
\hline 4 & Alkaloids & Maeyer's test & +ve \\
\hline 5 & Alkaloids & Wagner's Test & -ve \\
\hline 6 & Tannic Acid and Phenolic & Compounds test & +ve \\
\hline 7 & Sulphates & Sulphate Test & +ve \\
\hline 8 & Chlorides & Chloride Test & +ve \\
\hline 10 & Flavanoids & Flavanoid Test & +ve \\
\hline
\end{tabular}

Table 2: DPPH activity in D. Sissoo Leaves.

\begin{tabular}{|c|c|c|}
\hline Concentration & $\begin{array}{c}\text { Standard ascorbic } \\
\text { acid }\end{array}$ & Sheesham \\
\hline $.1 \mu \mathrm{g}$ & 1.031 & 0.148 \\
\hline $.2 \mu \mathrm{g}$ & 1.072 & 0.238 \\
\hline $.3 \mu \mathrm{g}$ & 1.073 & 0.308 \\
\hline $.4 \mu \mathrm{g}$ & 0.865 & 0.403 \\
\hline $.5 \mu \mathrm{g}$ & 0.966 & 0.431 \\
\hline
\end{tabular}

NO is an important bioregulatory molecule which has physiological effects such as control of blood pressure, neural signal transduction, platelet function, as well as antimicrobial and antitumor activities. Low concentrations of NO are sufficient, in most cases, to affect these beneficial functions. But during infections and inflammations the formation of NO gets elevated and can lead to undesired deleterious effects [36]. Presently the results of NO radical scavenging activity show that the results for the D. Sissoo leaves extract are higher as compared than the standards. Thus, confirming that the \% scavenging is higher as shown by Table 3 the present results show that D. Sissoo leaves extract have potentially high antioxidant activity.

Table 3: NO Scavenging activity in $D$. Sissoo Leaves.

\begin{tabular}{|c|c|c|}
\hline Concentration & $\begin{array}{c}\text { Standard Ascorbic } \\
\text { Acid }\end{array}$ & Sheesham \\
\hline $200 \mu \mathrm{g} / \mathrm{ml}$ & 25.6 & 110.2 \\
\hline $400 \mu \mathrm{g} / \mathrm{ml}$ & 23.2 & 125.5 \\
\hline $600 \mu \mathrm{g} / \mathrm{ml}$ & 26.7 & 131.4 \\
\hline $800 \mu \mathrm{g} / \mathrm{ml}$ & 24.5 & 131.8 \\
\hline $1000 \mu \mathrm{g} / \mathrm{ml}$ & 27.6 & 132.7 \\
\hline
\end{tabular}

Total antioxidant activity determination is based on the reduction of $\mathrm{Mo}(\mathrm{VI})$ to $\mathrm{Mo}(\mathrm{V})$ by the extract and subsequent formation of green phosphate/Mo(V) complex at acid $\rho \mathrm{H}$. Total antioxidant capacity of the phosphomolybdenum model evaluates both water-soluble and fat-soluble antioxidant capacity (total antioxidant capacity) [36]. The result for total antioxidant activity for D. Sissoo leaves extract is shown in Table 4.

Table 4: Total Antioxidant activity in D. Sissoo Leaves.

\begin{tabular}{|c|c|c|}
\hline Concentration & $\begin{array}{c}\text { Standard Ascorbic } \\
\text { Acid }\end{array}$ & Sheesam \\
\hline $200 \mu \mathrm{g} / \mathrm{ml}$ & 31.33 & 214.2 \\
\hline $400 \mu \mathrm{g} / \mathrm{ml}$ & 18.78 & 213.4 \\
\hline $600 \mu \mathrm{g} / \mathrm{ml}$ & 24.18 & 114.8 \\
\hline $800 \mu \mathrm{g} / \mathrm{ml}$ & 25.88 & 142.3 \\
\hline $1000 \mu \mathrm{g} / \mathrm{ml}$ & 30.13 & 138.5 \\
\hline
\end{tabular}

The total flavonoid content was calculated according to the standard methods. The absorbance is found to show an increasing trend with an increase in the concentration. The TFP of extracts were determined from regression equations for the calibration curve of Quercetin ( $y=0.0122 x+0.697$, $\mathrm{R} 2=0.9905)$. The total flavonoid content in D. Sissoo leaves extract was found to be $65.746 \mathrm{mg} / \mathrm{g}$. Total Phenolic content is measured using F-C method. F-C method is based on the transfer of electrons in alkaline medium from phenolic compounds to phosphomolybedic phosphotungstic acid complexes to form blue coloured complexes, (PMoW11040)-4 that are determined spectro-photometrically at $760 \mathrm{~nm}$. Total phenolic content of the extracts was calculated from the regression equation of calibration curve $\left(Y=0.007 x+0.0211 R^{2}=0.9932\right)$ and expressed as mg gallic acid equivalents (GE) per gram of sample in dry weight $(\mathrm{mg} / \mathrm{g})$. The total phenolic content in the D. Sissoo leaves extract is found to be $270.29 \mathrm{mg} / \mathrm{g}$ which is much higher as compared with the standard.

\section{Discussion}

The cellular components of the immune system comprise of many polyunsaturated fatty acids which are receptive to various oxidative attack leading to lipid peroxidation which is highly injurious. The products so formed are also highly cytotoxic. Many effects resulting due to these include generation of more ROS and radical derived products. The immunocompetence 


\section{Global Journal of Pharmacy \& Pharmaceutical Sciences}

decreases with age, poor nutrition and lack of nutrients leading to excessive generation of ROS (reactive oxygen species). Various antioxidants may prevent or correct immune dysfunction. Various chronic inflammatory disorders such as rheumatoid arthritis, psoriasis, inflammatory bowel diseases etc results into cytokinesis. These initiate the movement of the activated inflammatory and immune cells towards the site thus intensifying the inflammatory process. Many examples such as transcription factor NF- $\mathrm{KB}$ govern the expression of several genes. The agent that activates this factor includes ionisation radiation, $\mathrm{H}_{2} \mathrm{O}_{2}, \mathrm{OH}$ and ozone. Antioxidant prevention of NF- $\mathrm{KB}$ activation can be beneficial in overcoming the toxic effects such as acute inflammatory responses; graft vs host reactions and radiation damage [37]. Thus, immunomodulation can go hand in hand with antioxidant activity.

Oxidative stress may influence the immune system either by suppressing or hyper exciting autoimmune system resulting into susceptibility to infections. Drugs obtained from plants play a significant role in handling such problems. In the present study, it is found that D. Sissoo leaves extracts are enormous source of antioxidants. Various tests have been conducted to find the antioxidant activity in the methanolic extract of $D$. Sissoo leaves. It has already been found that herbal antioxidants concurrently exhibit significant immunomodulatory activities. Being a rich source of antioxidants, D. Sissoo leaves serve as an excellent source of immunomodulator.

\section{Conclusion}

Entire immune system is complex but is interconnected to various biochemical processes. It is vulnerable to oxidative stress and is potent to damage various molecules produced while the working of immune system. During ageing and diseased state antioxidants promotion is required which helps in building strong immune system. In this respect, various plants with higher antioxidant activity can be considered for their immunomodulating properties. In the present study, we have identified D. Sissoo leaves extract as a rich source of antioxidants thus can act as immunomodulator. These can inhibit the immune response, cell proliferation or may bring about selective inhibition of events. These may also have potent potential after radiotherapy or in ageing. There are many works yet to be done in this regard to employ these leave extracts into therapeutics. A systemic approach is required to identify the active constituents which are nontoxic, beneficial and are responsible for the antioxidant activity. Then these constituents can be further studied computationally as well as can be tested on animal models for immunomodulatory effects.

\section{References}

1. WHO (2011) The promotion and development of traditional medicine. Geneva: WHO, Switzerland, pp. 622.

2. Ravishankar B, Shukla VJ (2007) Indian Systems of Medicine: A Brief Profile. Afr J Tradit Complement Altern Med 4(3): 319-337.
3. WHO regional office for the western pacific (1993) Research guidelines for evaluating the safety and efficacy of herbal medicines. Manila, Philippines p. 94.

4. Schultes RE (1978) The Kingdom of Plants. In: Thompson WAR (Ed.), Medicines from the Earth. McGraw-Hill Book Co, New York, USA, pp: 208.

5. Agbor AG, Ngogang YJ (2010) Toxicity of herbal preparations. Cam J Ethnobot 1: 23-28.

6. Lobo VA Patil A, Phatak A, Chandra N (2010) Free radicals, antioxidants and functional foods: Impact on human health. Pharmacogn Rev 4(8): 118-126.

7. Sies H (1997) Oxidative stress: oxidants and antioxidants. Exp Physiol 82(2): 291-295

8. Vaibhav DA, Arunkumar W, Abhijit MP, Arvind S (2011) Antioxidants as Immunomodulator: An Expanding Research Avenue. International Journal of Current Pharmaceutical Research 3(1): 0975-7066.

9. Bafna A, Mishra S (2010) Antioxidant and Immunomodulatory Activity of the Alkaloidal Fraction of Cissampelospareira Linn Sci Pharm 78(1): 21-31.

10. Devagayasam TPA, Sainis KB (2001) Immune systems and Antioxidants, especially those derived from Indian Medicinal Plants, Ind Journal of Experimental Biology 40: 639-655.

11. Yogita A, Hajare SW, Ingawale MV, Bhojane NM, Madhuri $\mathrm{H}$, et al (2017) Anti-Inflammatory Activity of Ethanolic Leaf Extract of Dalbergia Sissoo In Vitro and In Vivo. Advances in Tissue Engineering and Regenerative Medicine 2(3): 2017.

12. Hajare SW, Chandra S, Sharma J, Tandan SK, Lal J, et al. (2001) Antiinflammatory activity of Dalbergia sissoo leaves. Fitoterapia 72(2): 131-139.

13. Al-Quran S (2008) Taxonomical and Pharmacological Survey of Therapeutic Plants in Jordan. Journal of Natural Products1: 10-26.

14. Yadav H, Yadav M, Jain S, Bhardwaj A, Singh V, et al. (2008) Antimicrobial property of a herbal preparation containing Dalbergia sissooand Datura tramoniumwith cow urine against pathogenic bacteria. Int J ImmunopatholPharmacol 21(4): 1013-1020.

15. Sharma PC, Yelne MB, Dennis TJ (2001) Database on medicinal plants used in ayurveda. Vol 2. New Delhi: Central Council for Research in Ayurveda and Siddha. Vedams eBooks, Delhi, India, pp. 481-489.

16. Ishtiaq MC, Khan MA, Hanif W (2006) Ethno Veterinary Medicinal Uses of Plants from Samahni Valley Dist. Bhimber, (Azad Kashmir) Pakistan. Journal of Plant Sciences 5 (2): 390-396.

17. Ahmad H (2005) Issues Regarding Medicinal Plants of Pakistan Udyana Today 6(3): 6-7.

18. Ansari MA, Razdan RK, Mamta T, Padma V (2000) Larvicidal and repellent actions of Dalbergia sissooRoxb. F Leguminosae oil against mosquitoes. Bioresource Technology 73(3): 207-211.

19. Kumari A, Kakkar P (2008) Screening of antioxidant potential of selected barks of Indian medicinal plants by multiple in vitro assays. Biomed Environ Sci 21(1): 24-29.

20. Ahmad SA (2007) Medicinal wild plants from Lahore Islamabad motorway (M-2). Pak J Bot 39(2): 355-375.

21. Hussain K, Shahazad A, Zia-ul-Hussnain S (2008) An Ethnobotanical Survey of Important Wild Medicinal Plants of Hattar District Haripur, Pakistan. Ethnobotanical Leaflets 12(1): 29-35.

22. Mukhtar HS, Irum M, Salik NK (2010) Medicinal Importance and Association of Pathological Constraints with Dalbergia Sissoo. Pak J Phytopathol 22 (2): 135-138. 
23. Ragab A, Mostafa SMI, El-Shami II, Abdel-Rahim S (2006) Bioactive fractions and compounds from dalbergia sissoo for the prevention or treatment of osteo-health related disorders. Mansoura journal of Pharmaceutical Science 22(2): 176-194.

24. Rana V, Kumar V, Soli PL (2009) Method of conversion of carbohydrate polymers to value-added chemical products. Carbohydrate polymers 78(3): 520-525.

25. Abdel-Ghani, Afaf E, Dora GA (2004) Mansoura journal of pharmaceutical science 20(1): 104-1 13.

26. Farag SF, Ahmed AS, Terashima K, Takaya Y, Niwa M (2001) Phytochemistry 57(8): 1263-1268, 2001

27. Banerji A, Murti VVS, Seshadri TR (1966) Indian Journal of Chemistry 4(2): 70-72.

28. Azmir J (2013) Techniques for extraction of bioactive compounds from plant materials: A review. Journal of Food Engineering 117 (2013): 426-436.

29. Harbone JB (1998) Phytochemical Methods- A Guide to Modern Techniques of Plant Analysis, Chapman and Hall London.

30. Brand-Williams, Cuvelier ME, Berset CLWT (1995) Use of a free radical method to evaluate antioxidant activity. LWT-Food Science and Technology 28(1): 25-30
31. Prieto P, Pineda M, Aguilar M (1999) Spectrophotometric quantitation of antioxidant capacity through the formation of a phosphomolybdenum complex: Specific application to the determination of Vitamin E1. Anal Biochem 269(2): 337-341.

32. Morsi RMY, Tahan NREL, El-Hadad AMA (2010) Effect of aqueous extract Mangifera Indica leaves, as functional foods. J ApplSci Res 6(6): 712-721.

33. Williams WB, Cuvelier ME, Berset C (1995) Use of a free radical method to evaluate antioxidant activity. Food Sci. Technology 28: 25-30.

34. Ito N, Hirose M, Fukushima S, Tsuda H, Shirai T, et al. (1986) Studies on antioxidants: their carcinogenic and modifying effects on chemical carcinogenesis. Food Chem Toxicol 24(10-11): 1099-1102.

35. Akhila S, Bindu AR, Bindu K, Aleykutty NA (2009) Comparative Evaluation of Extracts of Citrus limonBurm Peel for Antioxidant Activity. J Young Pharm 1(2): 136-140.

36. Shikha R, Savita D (2017) Screening of Phytochemicals In Citrus Limonum Peel Extract To Evaluate Its Antimicrobial Potential. International Journal of Natural Products Research 7(2): 7-16.

37. Baeuerle PA Henkel T (1994) Function and activation of NF-kB in the immune system, Annual Review Immunol 12: 141-176.

Your next submission with Juniper Publishers will reach you the below assets

- Quality Editorial service

- Swift Peer Review

- Reprints availability

- E-prints Service

- Manuscript Podcast for convenient understanding

- Global attainment for your research

- Manuscript accessibility in different formats

( Pdf, E-pub, Full Text, Audio)

- Unceasing customer service

Track the below URL for one-step submission https://juniperpublishers.com/online-submission.php 